\title{
Psychological Empowerment: Users and Professionals in Psychiatric Care before and after Mindfulness Treatment
}

\author{
Clive S. Michelsen'1, Peter Sundberg'2, Linda Ekstrand ${ }^{2}$, Torsten Norlander1,2* \\ ${ }^{1}$ Division of Research, Sciens College, Malmö, Sweden \\ ${ }^{2}$ Center for Research and Development, Evidens University College, Göteborg, Sweden \\ Email: *at.norlander@mailbox.tele2.se, clive.michelsen@sciens.se, petersundberg65@hotmail.se, linda.ekstrand@pe3.se
}

How to cite this paper: Michelsen, C. S., Sundberg, P., Ekstrand, L., \& Norlander, T. (2018). Psychological Empowerment: Users and Professionals in Psychiatric Care before and after Mindfulness Treatment. Psychology, 9, 1194-1207. https://doi.org/10.4236/psych.2018.95073

Received: April 13, 2018

Accepted: May 28, 2018

Published: May 31, 2018

Copyright $\odot 2018$ by authors and Scientific Research Publishing Inc. This work is licensed under the Creative Commons Attribution International License (CC BY 4.0).

http://creativecommons.org/licenses/by/4.0/

c. (i) Open Access

\begin{abstract}
The current study had two purposes, namely for the first time to investigate the degree of psychological empowerment (PE) before and after treatment with Mindfulness-Based Cognitive Therapy, and also for the first time to compare mental health users with professional healthcare providers in psychiatry in this respect. PE encompasses the processes that allow people greater control over their lives and to develop critical awareness of their sociopolitical environments. Participants were 14 mental health users ( 3 men and 11 women) and 19 professionals ( 1 man and 18 women) between the ages of 23 to 65 years. All of the users were out-patients and seven of them had more than one diagnosis. The majority of the users were diagnosed as having Recurrent Depression (11 individuals). The professional group consisted of mainly psychologists and psychotherapists. Both groups were undergoing Mindfulness-Based Cognitive Therapy with exactly the same structure and content. Results showed that the treatment increased PE and self-compassion for both users and professionals and the effect remained for at least three months. Concerning perceived feeling of security and perceived satisfaction, the professionals naturally felt more secure and satisfied before treatment but at after treatment and follow-up assessments, the users had caught up. In addition, the users also experienced improvements in physical and mental health, family relations and social relationships. It is therefore suggested that PE could be used to evaluate therapeutic outcomes in cognitive behavioral therapy, and furthermore could be introduced in therapist education for the purpose of deepening self-practice and self-reflection for both users and prospective therapists.
\end{abstract}

\section{Keywords}

Mindfulness-Based Cognitive Therapy, Perceived Feeling of Security, Psychological Empowerment, Self-Reflection, Therapist Education 


\section{Introduction}

Mindfulness based therapy is a therapeutic intervention that has been successfully used in a variety of psychiatric and psychological disorders. The technique is included in combination with cognitive behavior therapy (CBT) in various treatment programs (Baer, 2015) such as Acceptance and Commitment Therapy (ACT), Mindfulness-Based Stress Reduction (MBSR), Dialectical Behavior Therapy (DBT) and Mindfulness-Based Cognitive Therapy (MBCT). A meta-analysis with 39 studies showed that mindfulness is particularly useful for treating various forms of anxiety and mood disorders in clinical populations (Hofmann et al., 2010). Other studies indicate that the method also has the significance of relapse prevention of these disorders (Lilja et al., 2015; Lilja et al., 2016). Variables linked to mindfulness as self-compassion (Neff et al., 2007), perceived sense of security (Norlander et al., 2015), and client satisfaction (Angantyr et al., 2015) are inversely associated with negative states of mind such as depression, anxiety and stress and may therefore also function as indicators for successful treatment of mental health users (Norlander et al., 2015). A review of ten studies (Chiesa \& Serretti, 2009) revealed that the method is also beneficial for reducing stress levels for healthy people, which is in line with another review consisting of twenty articles with health care providers (Escuriex \& Labbé, 2011) where the conclusion was drawn that these persons benefited from mindfulness training through positive effects in terms of psychosocial ability and reduced stress experience. A further review of healthcare providers (Morgan et al., 2014) not only showed that stress levels were reduced but also that the quality of staff interaction with patients improved. They learned how to repeatedly shift focus between caring for others to take care of themselves.

A number of studies dealing with mindfulness based therapy describe that key themes of the treatment include empowerment of participants and a focus on awareness of experience in the moment (e.g., Cairns \& Murray, 2015; Ma \& Teasdale, 2004; Moore \& Martin, 2015; Teasdale et al., 2000; Wong et al., 2011). Efforts have been made to find quantitative solutions to operationalize and measure the "awareness of experience in the moment" through self-estimation forms of different experiences received by individuals in the state (Baer et al., 2006). However, we have not found any studies which quantitatively examined degree of empowerment before and after mindfulness treatment. Nor has it been possible to find studies which compared patients and healthy people after they have undergone mindfulness treatment in terms of outcome parameters, such as empowerment, self-compassion, perceived safety and perceived satisfaction.

Empowerment is a term used in several research areas (Castelein et al., 2008) and the concept has been analyzed from different perspectives such as organizational, community, and individual perspectives (Rappaport, 1987). Psychological empowerment $(\mathrm{PE})$ is not the same as individual-level empowerment (Christens, 2012) but is usually defined in terms of the psychological aspects of processes that allow people greater control over their lives, participate in democratic deci- 
sion-making and develop critical awareness of their sociopolitical environments (Zimmerman, 1995). This is in line with several studies showing that PE is positively correlated to participation in community activities (Rogers et al., 2010) and with studies that show positive relationships between PE and patient's involvement in their own care (Tambuyzer \& Audenhove 2015). A meta-analysis (Nordén, Malm, \& Norlander, 2012) consisting of 17 studies with 2263 users with psychiatric diagnosis showed that increased PE through Resource-group Assertive Community Treatment (RACT) led to significant improvements for the users in terms of symptoms, function and well-being. A study on the importance of social networks in relation to stigma and PE in users with schizophrenia (Sibitz et al., 2011) showed strong positive correlations between quality of life, social networking and $\mathrm{PE}$, which in turn correlated negatively with stigma and depression. PE is positively related to self-compassion (Stevenson \& Allen, 2017), patients' satisfaction concerning the care they receive (Tambuyzer \& Audenhove, 2015), personal recovery (Jorge-Monteiro \& Ornelas, 2014) and inversely with severity of psychiatric symptoms (Corrigan et al., 1999).

A systematic review of available PE scales (Cyril et al., 2015) identified 20 measuring instruments. Of these, only eight studies had used all three steps that in the review were considered essential for item development: i.e., literature review, previous qualitative research and interaction with expert panels. The eight scales cover various areas of health promotion such as social workers (Frans, 1993), Aboriginal Australians (Haswell et al., 2010), health care (Gagnon et al., 2006), youth involvement in tobacco control (Holden et al., 2005), but only one of them had as a direct purpose to measure empowerment for patients (users) of mental health services (Rogers et al., 1997). The Empowerment Scale (ES) by Rogers and associates (1997) is widely used and validated across countries and contexts as well as often credited for having good psychometric properties (e.g., Castelein et al., 2008; Hansson \& Björkman, 2005; Jorge-Monteiro \& Ornelas, 2014; Yamada \& Suzuki, 2007).

The current study had two purposes, namely: 1) for the first time investigate degree of psychological empowerment before and after treatment with mindfulness and 2) for the first time compare users with psychiatric diagnoses with professional healthcare providers in psychiatry and primary care regarding psychological empowerment before and after treatment with mindfulness.

\section{Methods}

\subsection{Participants}

In the study, 33 individuals participated in the ages of 23 to 65 years. With similar age distribution, they consisted of 14 users ( 3 men and 11 women) and 19 professionals ( 1 man and 18 women). In the user group, there were a number of diagnoses: Recurrent Depression (11 individuals), various types of Personality Disorders (4 individuals), Fatigue Depression (3 individuals), Bipolarity (2 individuals), GAD (2 individuals), Bulimia (1 individual), and Social Phobia (1 indi- 
vidual). Of the users 7 had more than one diagnosis. In addition, 9 users were associated with psychiatry and 5 users in primary care. All were out-patients. The professional group consisted mainly of psychologists/psychotherapists (11 individuals) but also social workers (5 individuals), physiotherapists ( 2 individuals), and one occupational therapist (1). Only one individual in the professional group medicated or received other psychological treatment during the study period.

\subsection{Instruments}

Empowerment Scale (ES). The instrument was designed to measure empowerment for users of mental health services (Rogers et al., 1997). In the current study, a Swedish translation was used (Hansson \& Björkman, 2005) which has excellent psychometric properties in terms of consistency and construct validity for the test's overall score. As for the subscales, the levels of psychometric properties were uneven, which meant that in the current study we only used the total scale. ES consists of 28 questions in which the participant receives four answer options, i.e., "agree completely", "agree", "does not agree" and "do not agree at all". The answers are then coded in numbers from 1 to 4 . The questions are either reversed so that "agree completely" gives 4 points or "do not agree at all" give 4 points, but the higher score always means higher psychological empowerment (PE). ES consists of five domains with a varied number of questions. Here is an example of an item from each domain: Self-esteem and self-efficacy ("I generally accomplish what I set out to do"), Power-powerlessness ("I feel powerless most of the time"), Community activism and autonomy ("People have a right to make their own decisions, even if they are bad ones"), Optimism and control over future ("People are limited only by what they think possible"), and Righteous anger ("Getting angry of something is often the first step toward changing it').

Self-Compassion Scale Short form (SCS-SF). The instrument (Raes, Pommier, Neff, \& van Gucht, 2011) is a short version of Self-Compassion Scale (Neff, 2003). In the current study, the short version was derived from a Swedish translation of SCS (Strömberg, 2010). The instrument contains 12 statements where each is assessed by the participant on a five-point scale, from "almost never" to "almost always". The instrument has high internal consistency $(\alpha=0.86)$ and a near perfect correlation with the long version of SCS $(r=0.97)$ (Raes et al., 2011). Higher scores indicate greater sense of self-compassion. Examples of items are: "I try to be understanding and patient towards those aspects of my personality I don't like, and "When something upsets me I try to keep my emotions in balance".

Perceived Feeling of Security (PFS). The scale (Norlander et al., 2015) consists of a visual analogue scale (VAS) with the question "How secure do you feel in your environment?" Security is defined in accordance with Segesten as "a perceived feeling of being free of worrisome or threatening phenomena" (Segesten, 1994: p. 6). The participants had to mark on a line with a length of one de- 
cimeter with anchor-points "Not to all secure"- "Very secure" evaluated from 0 to 100 . The scale is considered to have acceptable psychometric properties (Norlander et al., 2015).

Perceived Satisfaction (PerSat). This quality of life instrument is based on a query battery (Norlander et al., 2015) with eleven questions about levels of satisfaction in various aspects, which are answered on VAS scales from 0 (Not to all satisfied) to 100 (Very much satisfied). Examples of questions are: "How satisfied are you currently with your life?" and "How satisfied are you with your mental health?" Other areas included are satisfaction with regard to physical health, mental health, family life, social relations, housing, employment, financial situation, income and how satisfied the participant is in general with his/her life. The eleven scales correlated significantly with each other (inter-item correlation: $r=0.55$ ) and homogeneity testing (Cronbach's Alfa) indicated the value 0.93 , which together made it possible to take the average of the eleven scales as a measure of the participants' satisfaction.

Conditions After Treatment (CAT). The instrument consists of seven VAS scales (Norlander et al., 2015) designed to investigate patients' experienced effects of treatments on scales from 0 (Not at all) to 100 (Very much). Examples of questions are "Do you have ongoing health care contacts regarding your mental health?" and "Have your social relationships improved following your MBCT treatment?". Reliability testing (Cronbach's Alfa) indicated the value0.86. Since the questions asked could not be judged to have an obvious common underlying factor, they were analyzed individually.

\subsection{Design of the Intervention}

The Mindfulness-Based Cognitive Therapy (MBCT) was conducted as an education according to a model developed by Segal, Williams, and Teasdale (2012). The intervention is used to a relatively large degree in Sweden (Ingvarsson et al., 2014) and consists of 8 weekly meetings of 2.5 hours. The course is experience-based and each occasion contains meditations followed by group reflection. Each week had a certain theme that could include, for example, the role of thought processes in depression. During the course material with tasks and exercises was distributed to the participants and they were also encouraged to do their mindfulness training at home on a daily basis, between 30 - 40 minutes. Prior to the end of the education, each participant was asked to draw up a so-called relapse prevention plan with the aim that the participant after the course would meet the difficulties he/she may encounter by being more observant of different symptoms and how they could be handled in everyday life, for example through meditation, relaxation or strategies.

\subsection{Procedure}

The users were recruited through a psychiatric reception and a primary care unit in southwestern Sweden where they were asked whether they wanted to participate in mindfulness based cognitive therapy designed as a course. It was decided 
that about eight participants with recurrent depression diagnosis or/and with more than one diagnosis would be included in each treatment group. In order for users with complex problems to be offered, it was required that they should have undergone CBT treatment before starting the MBCT program. Users with psychosis diagnoses or who had addictive drugs were excluded from the study. Next step was a randomized recruitment procedure leading to two treatment groups with eight participants. The professionals were recruited to two groups through the training institution Naturligt Vis ordinary course activities for MBCT instructors. The education was conducted in such a way that the professionals were undergoing the course with exactly the same structure and content as the patient groups. One group was a commissioned education for primary care employees from the Västragötaland county council and the other group was one of the educational institution's ongoing training courses for instructors where participants register on the website.

All registered participants in all four groups received oral and written information about the planned study at the start of the course. It was emphasized that participation in the study meant that one was supposed to answer test instruments before the education, directly after the education, and three months after completion of the course. Furthermore, it was pointed out that participation was completely voluntary and could be terminated at any time without the need to state any reasons. Finally, it was pointed out that the report would be written in such a way that anonymity is fully secured. Eight course participants (two users and six professional) declined participation in the study. During the first day of the training, a survey was distributed to those included in the study consisting of the four instruments and questions on background data. After the eighth session, they had to once more complete the survey and hand it over to the instructor. A follow-up three months after the completion of the course was conducted either by sending the instruments home to the participants with a postponed reply, or if so preferred, they could submit the material at the respective reception. At this time, participants were also allowed to fill in information about the possible effects of the treatment.

\section{Ethical Considerations}

The study followed the ethical standards of the World Medical Association's Declaration of Helsinki concerning Ethical Principles of Medical Research Involving Human Subjects. Written informed consent was obtained. In addition, the study procedure was reviewed and approved by the ethical research committee at Sciens College.

\section{Results}

\subsection{Correlations}

Correlations were conducted (Pearson's $r 5 \%$ level) between the dependent variables with data collected prior to initiation of treatment, i.e., Empowerment 
Scale (ES), Self-Compassion Scale Short Form (SCS-SF), Perceived Feeling of Security (PFS), and Perceived Satisfaction (PerSat). The analysis showed that all variables correlated among themselves, but not at levels that risk multicollinearity, see Table 1.

Table 1. Correlations (Pearson's r) before treatment in regard to Empowerment Scale (ES), Self-Compassion Scale Short Form (SCS-SF), Perceived Feeling of Security (PFS) and Perceived Satisfaction (PerSat).

\begin{tabular}{ccccc}
\hline & ES & SCS-SF & PFS & PerSat \\
\hline ES & 1 & & & \\
SCS-SF & $0.61^{* *}$ & 1 & & \\
PFS & $0.69^{* *}$ & $0.48^{* *}$ & 1 & 1 \\
PerSat & $0.61^{* *}$ & $0.55^{* *}$ & $0.64^{* *}$ & \\
\hline
\end{tabular}

Note: ${ }^{*}$ Significant correlations at 0.01 level.

\subsection{Dependent Variables in Relation to Treatment}

Pillai's mixed MANOVA $(2 \times 3$ factorial design $)$ was conducted with Group (Users, Professionals) and Treatment (Before, After, Follow-up) as independent variables and with ES, SCS-SF, PFS and PerSat as dependent variables. The analysis showed significant effects for Treatment $\left(p=0.009\right.$, Eta $^{2}=0.66$, power $=$ $0.92)$, interaction Treatment $x$ Group $\left(p=0.030, E_{t a}{ }^{2}=0.60\right.$, power $\left.=0.81\right)$ but not for Group $\left(p=0.191\right.$, Eta $^{2}=0.25$, power $\left.=0.43\right)$.

Univariate F-tests showed significant effects for treatment for $\operatorname{ES}[F(2,46)=$ $5.49, p=0.007]$, SCS $[F(2,46)=16.39, p<0.001]$, PFS $[F(2,46)=3.50, p=$ $0.039]$ and PerSat $[F(2,46)=3.50, p=0.039]$. Post-hoc tests (Paired Samples t-tests, $5 \%$ level) showed a pattern where the participants received positive effects between the first test (before treatment) and the second test (after treatment), but not between the second test session and the third (follow-up) for psychological empowerment, self-compassion and perceived satisfaction. Regarding perceived feeling of security, analysis showed a significant difference between the first and third assessments as the participants experienced a greater perceived feeling of security at the follow-up. Regarding the interaction Treatment $x$ Group, univariate F-tests showed significant effects for PFS $[F(2,46)=$ 3.63, $p=0.034]$ and PerSat $[F(2,46)=11.37, p<0.001]$. Post-hoc tests (Independent Samples $t$-tests, $5 \%$ level) showed that the professionals were more secure and more satisfied before treatment compared to users, but at after treatment and follow-up assessments there were no differences between groups. For mean values and standard deviations see Table 2 .

\subsection{Conditions after Treatment}

An one-way MANOVA with Group as independent variable and with the seven scales from CAT as dependent variables, showed significant effects for physical 
Table 2. Means (M) and standard deviations (SD) for Group (Users, Professionals) concerning Before treatment (1), After treatment (2) and Follow-up (3), in regard to Empowerment Scale (ES), Self-Compassion Scale Short Form (SCS-SF), Perceived Feeling of Security (PFS) and Perceived Satisfaction (PerSat).

\begin{tabular}{ccccccc}
\hline & \multicolumn{2}{c}{ Users } & \multicolumn{2}{c}{ Professionals } & \multicolumn{2}{c}{ All } \\
\cline { 2 - 6 } ES 1 & $M$ & $S D$ & $M$ & $S D$ & $M$ & $S D$ \\
ES 2 & 2.86 & 0.31 & 3.12 & 0.16 & $3.01+$ & 0.27 \\
ES 3 & 3.01 & 0.32 & 3.24 & 0.36 & $3.15+$ & 0.36 \\
SCS-SF 1 & 3.11 & 0.35 & 3.24 & 0.21 & 3.19 & 0.27 \\
SCS-SF 2 & 2.60 & 0.56 & 3.16 & 0.63 & $2.93+$ & 0.66 \\
SCS-SF 3 & 3.99 & 0.66 & 3.45 & 0.60 & $3.27+$ & 0.65 \\
PFS 1 & $65.07^{*}+$ & 22.77 & $88.66^{*}$ & 13.05 & $78.65+$ & 21.13 \\
PFS 2 & $83.08+$ & 16.15 & 85.2 & 13.94 & 84.39 & 14.61 \\
PFS 3 & 78.96 & 20.10 & 90.63 & 11.62 & $86.13+$ & 16.13 \\
PerSat 1 & $47.22^{*}+$ & 13.84 & $68.70^{*}$ & 18.03 & $59.59+$ & 19.41 \\
PerSat 2 & $61.21+$ & 16.03 & 69.76 & 17.29 & $66.45+$ & 17.02 \\
PerSat 3 & 67.18 & 19.71 & 66.74 & 23.14 & 66.91 & 21.48 \\
\hline
\end{tabular}

Note: Significant differences between users and professionals ${ }^{*}$. Note: Significant differences between before and after or follow-up assessments + .

health $[F(1,24)=13.84, p=0.001]$, mental health $[F(1,24)=8.02, p=0.009]$, family relationship $[F(1,24)=23.67, p<0.001]$, social relations $[F(1,24)=$ $8.21, p=0.009]$ and economic conditions $[F(1,24)=15.00, p=0.001]$. However, in terms of healthcare contacts and work, no significant effects were present ( $p s>0.05$ ). Descriptive analysis showed that users had higher values on the scales, indicating that they were more likely to experience improved conditions regarding different health and social relationships compared to the professionals following the MBCT treatment. For mean values and standard deviations, see Table 3.

\section{Discussion}

The current study had two purposes, namely to investigate the degree of empowerment before and after treatment with mindfulness and compare users with psychiatric diagnoses to professional healthcare providers in psychiatry care and primary care before and after treatment with mindfulness.

The study showed no differences between the users and the professionals in how they responded with regard to psychological empowerment (PE). Statistical analyzes showed a pattern in which the participants received positive effects between the first test (before) and the second test (after), but not between the second test and the third (follow-up). The same pattern was also evident for self-compassion. Mindfulness thus gave increased PE and self-compassion for 
Table 3. Means (M) and standard deviations (SD) for Group (Users, Professionals) regarding theseven scales of Conditions After Treatment (CAT).

\begin{tabular}{|c|c|c|c|c|}
\hline \multirow{2}{*}{ Visual Analogue Scales from 0 (Not at all) to 100 (Very much) } & \multicolumn{2}{|c|}{ Users } & \multicolumn{2}{|c|}{ Professionals } \\
\hline & $M$ & $S D$ & $M$ & $S D$ \\
\hline 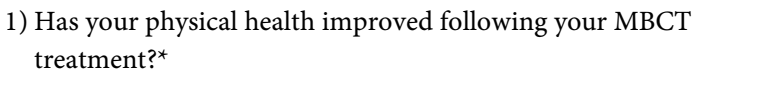 & 63.90 & 30.57 & 26.53 & 20.81 \\
\hline $\begin{array}{l}\text { 2) Has your mental health improved following your MBCT } \\
\text { treatment?* }\end{array}$ & 74.55 & 21.89 & 41.28 & 32.73 \\
\hline $\begin{array}{l}\text { 3) Has your family situation improved following your MBCT } \\
\text { treatment?* }\end{array}$ & 67.45 & 16.37 & 21.09 & 27.08 \\
\hline $\begin{array}{l}\text { 4) Have your social relationships improved following your MBCT } \\
\text { treatment?* }\end{array}$ & 55.20 & 33.91 & 20.06 & 28.12 \\
\hline 5) Has your treatment affected your work situation? & 56.75 & 36.00 & 40.13 & 24.81 \\
\hline 6) Has your treatment affected your financial situation?* & 26.72 & 26.18 & 1.31 & 3.81 \\
\hline $\begin{array}{l}\text { 7) Do you have ongoing health care contacts regarding your mental } \\
\text { health? }\end{array}$ & 19.40 & 33.32 & 7.81 & 22.04 \\
\hline
\end{tabular}

Note: Significant differences between users and professionals have been marked with *.

both users and care givers and the effect remained for at least three months. The two related characteristics appear to be core elements in the effects generated by mindfulness, which is in line with qualitative studies reporting that key themes of the treatment include empowerment of participants and a focus on awareness of experience in the moment including self-compassion (van Aalderen et al., 2014; Cairns \& Murray, 2015; Ma \& Teasdale, 2004; Moore \& Martin, 2015; Teasdale et al., 2000; Wong et al., 2011). However, the pattern became somewhat different for two other characteristics associated with PE, namely perceived feeling of security and perceived satisfaction where it was found that the care givers felt more secure and satisfied before treatment as compared to the users. But at after treatment and follow-up assessments, the users caught up and then there were no further differences with regard to group. Enhanced feelings of security and satisfaction in users may be indicators of ongoing rehabilitation (Norlander et al., 2015).

At the follow-up three months after completion of treatment, participants were given the opportunity to indicate how they experienced their situation using the instrument Conditions After Treatment (CAT). It was found that users experienced improved conditions regarding different health aspects and social relationships compared to the professionals. The users experienced, as expected, significant improvements in physical and mental health, family relation and social relationships. There was no difference in the impact on the work situation, nor is it surprising given that such changes are likely to require more time than three months to be manifested. On the other hand, it was interesting and promising with the low mean $(M=19.40, S D=33.32)$ for the users concerning item seven ("Do you have ongoing health care contacts regarding your mental health?") which indicates a success for the treatment. This is further emphasized by the fact that there was no significant difference between users and care pro- 
viders in relation to ongoing healthcare contacts.

The current study had some limitations. The first limitation was the relative low number of participants, 33 people. Nevertheless, it was quite possible to carry out statistical comparisons with respect to different measurements and in relation to group comparisons. One major problem was the particularly obscure distribution between men and women. The study had a large overweight of women, 29 individuals (88\%), which of course made it impossible to make statistical analyzes of this aspect. Further, the study only employed experimental groups with no use of a control-group. However, despite these limitations the current study has, for the first time, quantitatively analyzed the degree of PE after treatment with mindfulness and, for the first time compared the effects that this has given to users and care providers in psychiatry. Thus, perhaps a starting point has been created for new efforts in empowerment research. Future research may further investigate the practical meaning of the links between treatment with mindfulness based cognitive therapy and increased PE. The degree of $\mathrm{PE}$ could be an important measure for both users and care providers regarding the evaluation of therapeutic outcomes in cognitive behavioral therapy (Burn \& Lee, 2017) and assertive community treatment (Nordén, Eriksson, Kjellgren, \& Norlander, 2012).

One aspect that is repeatedly discussed in the programs for future psychotherapists is whether or not personal therapy is a necessary element for the student to develop skills as a therapist or whether alternatives such as systematizing self-reflections about different experiences that the student encounter during the training are equivalent or better (Macaskill, 1988). According to Bennett-Levy and associates (Bennett-Levy et al., 2009) there is no evidence to indicate the impact of personal therapy on CBT practice at the present time. Therefore, in CBT therapy, several self-reflection models have been developed such as supervision (Padesky, 1996), reflection in groups (Chaddock et al., 2006; Farrand et al., 2008) self-practice/self-reflection, which has come to be known as SP/SR (Bennett-Levy et al., 2001). A hypothesis in future research could be that psychological empowerment (PE) measured with the Empowerment Scale could be used in therapist education to improve and deepen self-practice and self-reflection for both users and prospective therapists. This could be an important complement to rating scales for assessing student therapist skills (Blackburn et al., 2001; Jervelycke et al., 2017), which is now common practice at several educational institutions.

\section{Acknowledgements}

The authors thank the participants for taking the time to participate in the study. A special thanks to Henrik Kok from Naturligt Vis Education, certified psychotherapist and certified physiotherapist, for valuable help and lots of good advice.

\section{Conflict of Interest}

The authors confirm that this article content has no conflicts of interest. 


\section{References}

Angantyr, K., Rimner, A., Nordén, T., \& Norlander, T. (2015). Primary Care Behavioral Health (PCBH) Model of Integrated Care: Perspectives of Outcome, Client Satisfaction, and Gender. Social Behavior and Personality, 43, 287-301. https://doi.org/10.2224/sbp.2015.43.2.287

Baer, R. A. (Ed.) (2015). Mindfulness-Based Treatment Approaches: Clinician's Guide to Evidence Base and Applications. London: Academic Press.

Baer, R. A., Smith, G. T., Hopkins, J., Krietemeyer, J., \& Toney, L. (2006). Using Self-Report Assessment Methods to Explore Facet of Mindfulness. Assessment, 13, 27-45. https://doi.org/10.1177/1073191105283504

Bennett-Levy, J., Thwaites, R., Chaddock, A., \& Davis, M. (2009). Reflective Practice in Cognitive Behavioural Therapy: The Engine of Lifelong Learning. In R. Dallos, \& J. Stedmon (Eds.), Reflective Practice in Psychotherapy and Counselling (pp. 115-135). New York: Open University Press.

Bennett-Levy, J., Turner, F., Beaty, T., Smith, M., Paterson, B., \& Farmer, S. (2001). The Value of Self-Practice of Cognitive Therapy Techniques and Self-Reflection in the Training of Cognitive Therapists. Behavioural and Cognitive Psychotherapy, 29, 203-220. https://doi.org/10.1017/S1352465801002077

Blackburn, I. M., James, I. A., Milne, D. L., Baker, C., Standart, S., Garland, A., \& Reichelt, F. K. (2001). The Revised Cognitive Therapy Scale (CTS-R): Psychometric Properties. Behavioural and Cognitive Psychotherapy, 29, 431-446.

https://doi.org/10.1017/S1352465801004040

Burn, K., \& Lee, L. (2017). Cognitive Behavioural Therapy in Palliative Care: Evaluation of Staff Following a Foundation Level Course. International Journal of Palliative Nursing, 23, 270-278. https://doi.org/10.12968/ijpn.2017.23.6.270

Cairns, V., \& Murray, C. (2015). How Do the Features of Mindfulness-Based Cognitive Therapy Contribute to Positive Therapeutic Change? A Meta-Synthesis of Qualitative Studies. Behavioural and Cognitive Psychotherapy, 43, 342-359.

https://doi.org/10.1017/S1352465813000945

Castelein, S., van der Gaag, M., Bruggeman, R., van Busschbach, J. T., \& Wiersma, D. (2008). Measuring Empowerment among People with Psychotic Disorders: A Comparison of Three Instruments. Psychiatric Services, 59, 1338-1342.

https://doi.org/10.1176/ps.2008.59.11.1338

Chaddock, A., Thwaites, R., Freeston, M., Bennet-Levy, J. (2006). Can Self-Practice/Self-Reflection Enhance the Therapeutic Skills and Attitudes of Trainee Cognitive-Behavioural Therapists? EABCP Conference Presentation, Paris.

Chiesa, A., \& Serretti, A. (2009). Mindfulness-Based Stress Reduction for Stress Management in Healthy People: A Review and Meta-Analysis. The Journal of Alternative and Complementary Medicine, 15, 593-600. https://doi.org/10.1089/acm.2008.0495

Christens, B. D. (2012). Toward Relational Empowerment. American Journal of Community Psychology, 50, 114-128. https://doi.org/10.1007/s10464-011-9483-5

Corrigan, P. W., Faber, D., Rashid, F., \& Leary, M. (1999). The Construct Validity of Empowerment among Consumers of Mental Health Services. Schizophrenia Research, 38, 77-84. https://doi.org/10.1016/S0920-9964(98)00180-7

Cyril, S., Smith, B. J., \& Renzaho, A. M. (2015). Systematic Review of Empowerment Measures in Health Promotion. Health Promotion International, 31, 809-826. https://doi.org/10.1093/heapro/dav059

Escuriex, B. F., \& Labbé, E. E. (2011). Health Care Providers' Mindfulness and Treatment 
Outcomes: A Critical Review of the Research Literature. Mindfulness, 2, 242-253. https://doi.org/10.1007/s12671-011-0068-Z

Farrand, P., Perry, J., \& Linsley, S. (2008). Enhancing SP/SR through the Use of Reflective Blogs. BABCP Conference Presentation, Edinburgh.

Frans D. J. (1993). A Scale for Measuring Social Worker Empowerment. Research on Social Work Practice, 3, 312-328. https://doi.org/10.1177/104973159300300305

Gagnon, M., Hébert, R., Dubé, M., \& Dubois, M. F. (2006). Development and Validation of an Instrument Measuring Individual Empowerment in Relation to Personal Health Care: The Health Care Empowerment Questionnaire (HCEQ). American Journal of Health Promotion, 20, 429-435. https://doi.org/10.4278/0890-1171-20.6.429

Hansson, L., \& Björkman, T. (2005). Empowerment in People with a Mental Illness: Reliability and Validity of the Swedish Version of an Empowerment Scale. Scandinavian Journal of Caring Sciences, 19, 32-38. https://doi.org/10.1111/j.1471-6712.2004.00310.x

Haswell, M. R., Kavanagh, D., Tsey, K., Reilly, L., Cadet-James, Y., Laliberte, A. et al. (2010). Psychometric Validation of the Growth and Empowerment Measure (GEM) Applied with Indigenous Australians. Australian \& New Zealand Journal of Psychiatry, 44, 791-799. https://doi.org/10.3109/00048674.2010.482919

Hofmann, S. G., Sawyer, A. T., Witt, A. A., \& Oh, D. (2010). The Effect of Mindfulness-Based Therapy on Anxiety and Depression: A Meta-Analytic Review. Journal of Consulting and Clinical Psychology, 78, 169-183. https://doi.org/10.1037/a0018555

Holden, D. J., Evans, W. D., Hinnant, L. W., \& Messeri, P. (2005). Modeling Psychological Empowerment among Youth Involved in Local Tobacco Control Efforts. Health Education \& Behavior, 32, 264-278. https://doi.org/10.1177/1090198104272336

Ingvarsson, T., Nordén, T., \& Norlander, T. (2014). Mindfulness-Based Cognitive Therapy: A Case Study on Experiences of Healthy Behaviors by Clients in Psychiatric Care. Open Journal of Medical Psychology, 3, 390-402.

https://doi.org/10.4236/ojmp.2014.35041

Jervelycke, A., Larsson, B., \& Norlander T. (2017). Attitudes to Group Assessments: Prospective Psychotherapists' Experiences of Being Assessed by Fellow Students. Open Journal of Medical Psychology, 6, 179-196. https://doi.org/10.4236/ojmp.2017.63015

Jorge-Monteiro, M. F., \& Ornelas, J. H. (2014). Properties of the Portuguese Version of the Empowerment Scale with Mental Health Organization Users. International Journal of Mental Health Systems, 8, 48. https://doi.org/10.1186/1752-4458-8-48

Lilja, J. L., Broberg, M., Norlander, T., \& Broberg, A. G. (2015). Mindfulness-Based Cognitive Therapy: Primary Care Patients' Experiences of Outcomes in Everyday Life and Relapse Prevention. Psychology, 6, 464-477. https://doi.org/10.4236/psych.2015.64044

Lilja, J. L., Zelleroth, C., Axberg, U., \& Norlander, T. (2016). Mindfulness-Based Cognitive Therapy Is Effective as Relapse Prevention for Patients with Recurrent Depression in Scandinavian Primary Health Care. Scandinavian Journal of Psychology, 57, 464-472. https://doi.org/10.1111/sjop.12302

Ma, S. H., \& Teasdale, J. D. (2004). Mindfulness-Based Cognitive Therapy for Depression: Replication and Exploration of Differential Relapse Prevention Effects. Journal of Consulting and Clinical Psychology, 72, 31-40. https://doi.org/10.1037/0022-006X.72.1.31

Macaskill, N. D. (1988). Personal Therapy in the Training of the Psychotherapist: Is It Effective? British Journal of Psychotherapy, 4, 219-226.

Moore, K. M., \& Martin, M. E. (2015). Using MBCT in a Chronic Pain Setting: A Qualitative Analysis of Participants' Experiences. Mindfulness, 6, 1129-1136. 
https://doi.org/10.1007/s12671-014-0363-6

Morgan. P, Simpson. J., \& Smith. A. (2014). Health Care Workers Experiences of Mindfulness Training: A Qualitative Review. Mindfulness, 6, 744-758. https://doi.org/10.1007/s12671-014-0313-3

Neff, K. D., Kirkpatrick, K. L., \& Rude, S. S. (2007). Self-Compassion and Adaptive Psychological Functioning. Journal of Research in Personality, 41, 139-154. https://doi.org/10.1016/j.jrp.2006.03.004

Nordén, T., Eriksson, A., Kjellgren, A., \& Norlander, T. (2012). Involving Clients and Their Relatives and Friends in the Psychiatric Care: Case Managers' Experiences of Training in Resource Group Assertive Community Treatment. PsyCh Journal, 1, 15-27. https://doi.org/10.1002/pchj.1

Nordén, T., Malm, U., \& Norlander, T. (2012). Resource Group Assertive Community Treatment (RACT) as a Tool of Empowerment for Clients with Severe Mental Illness: A Meta-Analysis. Clinical Practice \& Epidemiology in Mental Health, 8, 144-151. https://doi.org/10.2174/1745017901208010144

Norlander, T., Ernestad, E., Moradiani, Z., \& Nordén, T. (2015). Perceived Feeling of Security: A Candidate for Assessing Remission in Borderline Patients? The Open Psychology Journal, 8, 146-152. https://doi.org/10.2174/1874350101508010146

Padesky, C. A. (1996). Developing Cognitive Therapist Competency: Teaching and Supervision Models. In P. M. Salkovskis (Ed.), Frontiers of Cognitive Therapy (pp. 266-292). New York: Guilford Press.

Raes, F., Pommier, E., Neff, K. D., \& van Gucht, D. (2011). Construction and Factorial Validation of a Short Form of the Self-Compassion Scale. Clinical Psychology \& Psychotherapy, 18, 250-255. https://doi.org/10.1002/cpp.702

Rappaport, J. (1987). Terms of Empowerment/Exemplars of Prevention: Toward a Theory for Community Psychology. American Journal of Community Psychology, 15, 121-142. https://doi.org/10.1007/BF00919275

Rogers, E. S., Chamberlin, J., Ellison, M. L., \& Crean, T. (1997). A Consumer-Constructed Scale to Measure Empowerment among Users of Mental Health Services. Psychiatric Services, 48, 1042-1047. https://doi.org/10.1176/ps.48.8.1042

Rogers, E. S., Ralph, R. O., \& Salzer, M. S. (2010). Validating the Empowerment Scale with a Multisite Sample of Consumers of Mental Health Services. Psychiatric Services, 61, 933-936. https://doi.org/10.1176/ps.2010.61.9.933

Segal, Z. V., Williams, J. M. G., \& Teasdale, J. D. (2012). Mindfulness-Based Cognitive Therapy for Depression. New York: Guilford Press.

Segesten, K. (1994). Patients' Perceptions of Security and Insecurity. Gothenburg, Sweden: K \& K Förlag AB.

Sibitz, I., Amering, M., Unger, A., Seyringer M. E., Bachmann, A., Schrank B., Benesch, T., Schulze, B., \&Woppmann A. (2011). The Impact of the Social Network, Stigma and Empowerment on the Quality of Life in Patients with Schizophrenia. European Psychiatry, 26, 28-33. https://doi.org/10.1016/j.eurpsy.2010.08.010

Stevenson, O., \& Allen, A. B. (2017). Women's Empowerment: Finding Strength in Self-Compassion. Women \& Health, 57, 295-310. https://doi.org/10.1080/03630242.2016.1164271

Strömberg, B. (2010). A Swedish Version of the Self-Compassion Scale (SCS). Lund, Sweden: Department of Psychology, Lund University.

Tambuyzer, E., \& Audenhove, C. (2015). Is Perceived Patient Involvement in Mental Health Care Associated with Satisfaction and Empowerment? Health Expectations, 18, 
516-526. https://doi.org/10.1111/hex.12052

Teasdale, J. D., Segal, Z. V., Williams, J. M. G., Ridgeway, V. A., Soulsby, J. M., \& Lau, M. A. (2000). Prevention of Relapse/Recurrence in Major Depression by Mindfulness-Based Cognitive Therapy. Journal of Consulting and Clinical Psychology, 68, 615-623.

van Aalderen, J. R., Breukers, W. J., Reuzel, R. P., \& Speckens, A. E. (2014). The Role of the Teacher in Mindfulness-Based Approaches: A Qualitative Study. Mindfulness, 5, 170-178. https://doi.org/10.1007/s12671-012-0162-x

Wong, S. Y., Mak, W. W., Cheung, E. Y., Ling, C. Y., Lui, W. W., Tang, W. K. et al. (2011). A Randomized, Controlled Clinical Trial: The Effect of Mindfulness-Based Cognitive Therapy on Generalized Anxiety Disorder among Chinese Community $\mathrm{Pa}$ tients: Protocol for a Randomized Trial. BMC Psychiatry, 11, 187.

https://doi.org/10.1186/1471-244X-11-187

Yamada, S., \& Suzuki, K. (2007). Application of Empowerment Scale to Patients with Schizophrenia: Japanese Experience. Psychiatry and Clinical Neurosciences, 61, 594-601. https://doi.org/10.1111/j.1440-1819.2007.01723.x

Zimmerman, M. A. (1995). Psychological Empowerment: Issues and Illustrations. American Journal of Community Psychology, 23, 581-599.

https://doi.org/10.1007/BF02506983 